\title{
Stabilization of Ball-On-Sphere System with Super Twisting (ST) Sliding Mode Control (SMC) as a Method of Chattering Reduction
}

\author{
Usman Mohammed \\ Department of Elect/Elect Engineering, Nile University of Nigeria, Abuja, Nigeria \\ E-mail: usman070064@nileuniversity.edu.ng \\ Suleiman U. Hussein \\ Department of Elect/Elect Engineering, Nile University of Nigeria, Abuja, Nigeria \\ Gokhan Koyunlu \\ Department of Computer Engineering, Nile University of Nigeria, Abuja, Nigeria
}

Received: 28 May 2020; Accepted: 25 July 2020; Published: 08 October 2020

\begin{abstract}
A SMC for the ball-on-sphere system was designed in this work. The mathematical system's model was first derived and a SMC was designed. Then, Lyapunov's method was used to test for the convergence on the sliding surface, and convergence of the system's states to the sliding surface was guaranteed. To reduce chattering, a super twisting SMC was designed. A controller that is linear was first given to the system and the simulation results showed that, while there is disturbance, achieving origin's asymptotic stability is not viable. A SMC was then applied next, while there is disturbance, origin's asymptotic stability was attained in finite-time. Then a 2nd order SMC was applied and the results showed faster origin's asymptotic stability in finite time. Therefore, the real effect of applying a 2nd order SMC is faster asymptotic stability of the origin. To reduce chattering, a ST SMC was applied and the chattering was observed to be reduced efficiently.
\end{abstract}

Index Terms: SMC; ST SMC; Ball-on-sphere; Chattering; System

\section{Introduction}

For control engineering research and education, a lot of experimental setups for control laboratory, such as inverted wedge, inverted pendulum, and ball and beam [1], [2], [3], have been explored over the past decades. Experiments of these setups are often not stable, under actuated, and inherently nonlinear and because of that, they are testbeds for nonlinear control engineering research.

For nonlinear control systems, there are some challenging, and perhaps popular, testbed. One of them is the ball-onsphere system which could be considered a balancing system. The basic components of the system are; 2 motors, a sphere, and 2 friction wheels [4]. The motors drive the friction wheels. The ball on the sphere's top can be balanced by controlling, along the horizontal axes, the sphere's rolling. This balancing is the main control objective of ball-on-sphere system. Because the system is under-actuated in nature, nonlinear, and unstable, controlling becomes a challenging task [5].

As an important balancing system, the system of ball-on-sphere finds applications from aerospace and transportation to robotics engineering. These application areas include rockets and space-ships' modelling and stabilization, humanoid robot or human postural standing modelling, self-transport machine, missile guidance, and robotic upper limit or human's unstable system modelling and simulation [6].

There are so many uncertain system class. One of the most powerful methodologies in controlling these kinds of systems is the sliding mode control (SMC). Some perturbations act in the control input's directions. These kinds of perturbations are called matched perturbations. The sliding mode controller consists of a switching term, of a highfrequency, that thoroughly indemnifies matched perturbations. The action of indemnifying matched perturbations happens when the trajectory stays on the "sliding manifold". A sliding manifold is the state space' subspace [7].

Constraining the movement of the closed-loop's state paths to reach the default sliding surface and to keep their motion on the, for all succeeding time, sliding surface using a law of switching control that is of high speed is the SMC's main idea. The system dynamics are ordained to compel its evolution on the default sliding surface when the state trajectories' motion is restricted to the sliding surface. This way, the system becomes unaffected by external disturbance and parametric variation [8]. 
The control objectives define the sliding surface. And based on the performance required in the closed-loop, discontinuous control synthesis is done to make the sliding system paths get to the sliding surface. This happens regardless of parametric variations and uncertainties [9].

The phenomenon whereby oscillations, of finite-amplitudes, finite-frequency, appear in systems employing SMC is described as chattering [10]. Small actuators' time constant, switching imperfections, and time delays in switching caused these oscillations. Consequently, in the sliding surface's neighbourhood, chattering is produced by the discontinuity in the feedback control [11]. Closed-loop control system's un-modelled dynamics excitation of sliding mode controller highfrequency switching can also cause these oscillations. The neglected dynamics in the process of system modelling are unmodelled dynamics. This could be of the neglected dynamics of the actuators and sensors. And these, un-modelled dynamics, are considerably faster than the dynamics of the main system [10]. Consequently, leading to problems such as mechanical parts heating, saturation, and consumption of significant energy [12] and also, electrical power circuits' significant heat losses and significant wear and tear for the moving mechanical parts [10].

One of the techniques for chattering reduction is the super twisting slide mode controller (ST-SMC). A similar rejection of disturbance and robustness properties of SMC can be provided by ST-SMC without the effect of chattering. ST-SMC suppresses the effect of chattering, therefore, its introduction in literature is a substantial breakthrough because the main downside of the ordinary SMC is chattering effect [13].

For the analysis of a nonlinear system, one of the powerful tools is the direct method of Lyapunov. The method is about generalized energy notion associated with systems of mechanical domain: if the total energy of a mechanical system decreases in all-time instances, then the mechanical system's motion is stable. Construction of an energy-like function that is scalar, called "Lyapunov function", and checking if it decreases in all-time instances is the main idea behind nonlinear systems stability analysis using the direct method. The generality of this method makes it powerful: it can be applied to all control systems' kinds, linear or nonlinear, time varying, infinite dimensional, time invariant, finite-dimensional, timeinvariant. Nevertheless, the method has its limitation which is the difficulty in finding the Lyapunov function [8].

This paper aims to design a SMC for ball-on-sphere system.

To achieve the aim of the paper the following objectives will be executed and these objectives are the relevance to the aim of the research;

- Investigation of the system dynamics and derivation of system's mathematical model.

- Designing of SMC for the system.

- $\quad$ Testing for convergence on the sliding surface using Lyapunov's method.

- Designing of ST SMC for chattering reduction.

\section{Literature review}

The system of the ball-on-sphere laboratory experimental control problem is considered in [14]. They showed that system decoupling, around the equilibrium, into 2 separately ball and wheel systems is viable. To achieve closed-loop system's stability, they designed a controller and the design was done based on SMC and full-state-feedback linearization. The control scheme's effectiveness is validated and demonstrated by the experimental and simulation results.

Sliding mode of a high order and dynamic SMC are studied in [15]. The additional dynamics added by the dynamic SMC can be regarded as compensators. An augmented system is the sliding system that has compensators. These compensators can also be called extra dynamics and are desired for a system's stability improvement and getting the desired performance and behaviour of the system.

The armature current and shaft speed are controlled in [16] as output variables. Separately excited DC motor is manipulated by its armature and field voltages variables. To alleviate the error of steady-state and peak overshoot of the DC motor variable structure systems based on SMC is used. Based on the obtained results, there is very little impact of outputs change on each other and against input disturbances, the controller is robust. MATLAB/SIMULINK was used to simulate the model.

An SMC that is hierarchical and that is state-dependent switching gain based is proposed in [17] for under actuated mechanical systems stabilization. 1st-level and 2nd-level sliding surfaces are the basis of the controller. The Lyapunov stability theorem was used in proving the surfaces' asymptotic stability. For the enactment of the suggested technique of control, 2 mechanical systems that are nonlinear and under actuated are used and numerical simulation is used to verify the feasibility. Bounded external disturbances are tackled efficiently by the proposed controller and robust performance is observed. When the convergence rate is compared with that of the integral SMC and ordinary SMC, it is observed that the proposed controller's rate is faster.

Nonlinear systems with active suspension are controlled in [18] using the dynamic SMC scheme. The sliding surface function, in the proposed scheme, is formed linearly with control inputs and system states. In the construction of the SM feedback controller, a term of fuzzy dynamic is utilized. Results show that the perturbations of the system did not affect the achievement of the sliding mode.

For a bi-directional DC-DC converter, a 2nd order SMC based on ST-SMC is used in [19]. 2 sliding mode controllers are designed for boost and buck modes DC-DC converter which could be switched to realize the current/voltage output regulation for different DC-DC converter working conditions. Simulation is done in PLECS for different DC-DC converter 
working conditions. The results show the robustness and better performance for the 2nd order SMC for bi-directional DCDC converter when compared with PID.

Under unknown external disturbances and model uncertainties, a novel adaptive ST-SMC for micro-gyroscope is proposed in [20]. They employed a high order ST-SMC strategy for the accuracy of trajectory tracking and regulation and improvement of the rate of convergence of reaching the sliding surface. This strategy not only combines the advantage of the conventional SMC with ST-SMC but also ensures that, for any initial state, the control system that's designed can get to the sliding surface and equilibrium in a lessened finite time and chattering problems are avoided. Lyapunov theory of stability is used to design an adaptive algorithm for the estimation of the angular velocity and unknown parameters of the micro-gyroscope. Finally, the simulation results show the proposed scheme's effectiveness. By comparative analysis study, ST-SMC is found out to be superior to the conventional SMC.

For robot manipulator's position tracking with external disturbances and uncertainties of parameter, an improved SMC scheme, which is the reformed conventional SMC approach, is developed in [21]. The scheme uses saturated-type SMC laws. It is shown that the asymptotic stability is achieved. The advantage of the proposed scheme can be seen from the simulation results.

[22] deals with sliding modes as a principle mode of operation, variable structure system's design aspects, basic concepts, and mathematics. Data processing and control algorithms that are used in systems of a variable structure are analysed. Control functional goals and electric drives' versatility as SMC methodology potential is demonstrated.

SMC of DC drives is considered in [23]. Dynamic modelling of DC machine and sliding mode control design are given.

A guide, for practicing control engineers, to SMC is presented in [24]. An accurate assessment of the chattering phenomenon is offered. Also, control design solutions for catalogues implementable SMC and a reference frame for future research in SMC are provided.

The remaining part of the paper is ordered in the following sequence. The system dynamics and derivation of system's mathematical model is presented where system equations are derived. Then, a SMC is designed for the system. Followed by convergence test on the sliding surface using Lyapunov's method. A ST SMC is then designed for chattering reduction. After that, simulation, analysis, results, and discussions are presented. Finally, a conclusion is drawn from the obtained results.

\section{Dynamic and mathematical modeling of ball-on-sphere system}

Model of the system is adopted and dynamical equations are derived [5], [25]. Independency is assumed, in all directions, around the point of equilibrium which means the system can be considered linear even though the dynamic equations are nonlinear and this means that interdependency of their parameters in various directions. With these assumptions, the system can be considered 2-D in all directions. With this, it is simplified to a system of ball and wheel. The system parameters are; $\beta_{\mathrm{x}}, \theta_{\mathrm{x}}$ which are angles of sphere and ball in the $\mathrm{x}$-direction, $\beta_{\mathrm{y}}, \theta_{\mathrm{y}}$ which are angles of sphere and ball in the y-direction, $\mathrm{I}_{\mathrm{B}}$ and $\mathrm{I}_{\mathrm{b}}$ which are ball and sphere's moments of inertia and $\mathrm{m}$ mass is ball's mass, $\mathrm{R}$ and $\mathrm{r}$ which are ball and sphere radii [26].

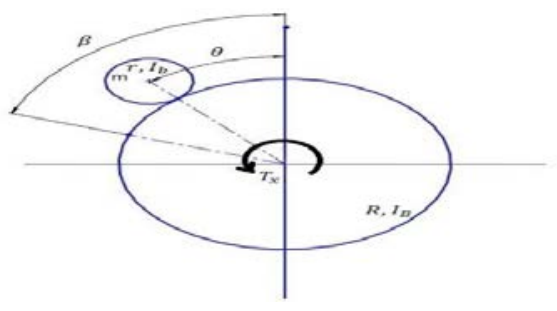

Fig. 1. System's schema in 2-D [14].

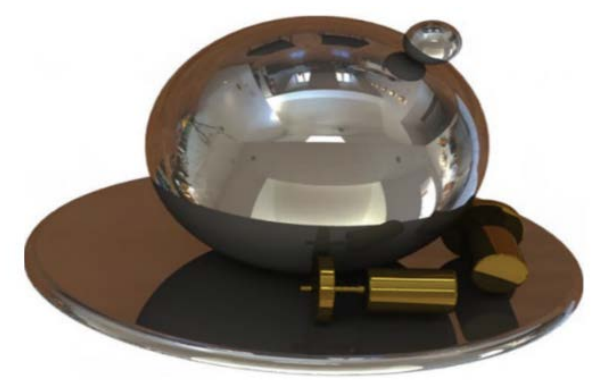

Fig. 2. System of ball-on-sphere [26]. 
Equations are derived using the Euler-Lagrangian method as follows [27]:

$$
\mathrm{L}=\mathrm{T}-\mathrm{V}
$$

where $\mathrm{V}$ is the potential energy $\mathrm{L}$ is the Lagrangian, $\mathrm{T}$ is the kinetic energy.

$$
\frac{\partial}{\partial \mathrm{t}}\left(\frac{\partial \mathrm{L}}{\partial \dot{\mathrm{q}}}\right)-\frac{\partial \mathrm{L}}{\partial \mathrm{q}}=\mathrm{Q}_{\mathrm{i}}, \mathrm{i}=1,2,3,4
$$

where $\mathrm{Q}$ is the generalized torque, $\mathrm{q}$ the generalized coordinate and torque and.

$$
\begin{gathered}
\mathrm{Q}_{1}=0 \quad \mathrm{Q}_{2}=\mathrm{T}_{\mathrm{x}} \quad \mathrm{Q}_{3}=0 \quad \mathrm{Q}_{4}=\mathrm{T}_{\mathrm{y}} \\
\left((\mathrm{R}+\mathrm{r}) \mathrm{m}+\mathrm{I}_{\mathrm{b}} \frac{\mathrm{R}+\mathrm{r}}{\mathrm{r}^{2}}\right) \ddot{\theta}_{\mathrm{x}}+\left(-\mathrm{I}_{\mathrm{b}} \frac{\mathrm{R}}{\mathrm{r}^{2}}\right) \ddot{\beta}_{\mathrm{x}}-\mathrm{mg} \sin \left(\theta_{\mathrm{x}}\right)=0 \\
\left(-\mathrm{I}_{\mathrm{b}} \frac{\mathrm{R}(\mathrm{R}+\mathrm{r})}{\mathrm{r}^{2}}\right) \ddot{\theta}_{\mathrm{x}}+\left(\mathrm{I}_{\mathrm{B}}+\mathrm{I}_{\mathrm{b}} \frac{\mathrm{R}^{2}}{\mathrm{r}^{2}}\right) \ddot{\beta}_{\mathrm{x}}=\mathrm{T}_{\mathrm{x}} \\
\left((\mathrm{R}+\mathrm{r}) \mathrm{m}+\mathrm{I}_{\mathrm{b}} \frac{\mathrm{R}+\mathrm{r}}{\mathrm{r}^{2}}\right) \ddot{\theta}_{\mathrm{y}}+\left(-\mathrm{I}_{\mathrm{b}} \frac{\mathrm{R}}{\mathrm{r}^{2}}\right) \ddot{\beta}_{\mathrm{y}}-\mathrm{mg} \sin \left(\theta_{\mathrm{y}}\right)=0 \\
\left(-\mathrm{I}_{\mathrm{b}} \frac{\mathrm{R}(\mathrm{R}+\mathrm{r})}{\mathrm{r}^{2}}\right) \ddot{\theta}_{\mathrm{y}}+\left(\mathrm{I}_{\mathrm{B}}+\mathrm{I}_{\mathrm{b}} \frac{\mathrm{R}^{2}}{\mathrm{r}^{2}}\right) \ddot{\beta}_{\mathrm{y}}=\mathrm{T}_{\mathrm{y}}
\end{gathered}
$$

We linearize the system about the point of equilibrium by taking the angles, $\theta$ and $\beta$, to be small at the point [28]. That is $\sin (\theta)=\theta, \cos (\theta)=1, \cos (\beta)=1$ and $\sin (\beta)=\beta$.

Then putting these assumptions into equations (4) - (7) gives;

$$
\begin{gathered}
\mathrm{a} \ddot{\theta}_{\mathrm{x}}+\mathrm{b} \ddot{\beta}_{\mathrm{x}}-\operatorname{mg} \theta_{\mathrm{x}}=0 \\
\mathrm{c} \ddot{\theta}_{\mathrm{x}}+\mathrm{d} \ddot{\beta}_{\mathrm{x}}=\mathrm{T}_{\mathrm{x}} \\
\mathrm{a} \ddot{\theta}_{\mathrm{y}}+\mathrm{b} \ddot{\beta}_{\mathrm{y}}-\mathrm{mg} \theta_{\mathrm{y}}=0 \\
\mathrm{c} \ddot{\theta}_{\mathrm{y}}+\mathrm{d} \ddot{\beta}_{\mathrm{y}}=\mathrm{T}_{\mathrm{y}}
\end{gathered}
$$

where

$$
a=\left((R+r) m+I_{b} \frac{R+r}{r^{2}}\right), b=\left(-I_{b} \frac{R}{r^{2}}\right), c=\left(-I_{b} \frac{R(R+r)}{r^{2}}\right), d=\left(I_{B}+I_{b} \frac{R^{2}}{r^{2}}\right)
$$

So, equations (8) - (11) are the linearized model of the ball-on-sphere system. These equations can be separated into the ball's and sphere's equation of motion, respectively.

$$
\begin{gathered}
\left\{\begin{array}{l}
\ddot{\theta}_{\mathrm{x}}=c_{1} \theta_{\mathrm{x}}+\mathrm{c}_{2} \mathrm{~T}_{\mathrm{x}} \\
\ddot{\theta}_{\mathrm{y}}=\mathrm{c}_{1} \theta_{\mathrm{y}}+\mathrm{c}_{2} \mathrm{~T}_{\mathrm{y}}
\end{array}\right. \\
\left\{\begin{array}{l}
\ddot{\beta}_{\mathrm{x}}=\mathrm{c}_{3} \theta_{\mathrm{x}}+\mathrm{c}_{4} \mathrm{~T}_{\mathrm{x}} \\
\ddot{\beta}_{\mathrm{y}}=\mathrm{c}_{3} \theta_{\mathrm{y}}+\mathrm{c}_{4} \mathrm{~T}_{\mathrm{y}}
\end{array}\right.
\end{gathered}
$$

where

$$
c_{1}=\frac{m g d}{a d-b c} \quad c_{2}=-\frac{b}{a d-b c} \quad c_{3}=\frac{m g c}{b c-a d} \quad c_{4}=-\frac{a}{b c-a d}
$$

Assuming $\mathrm{T}_{\mathrm{x}}$ and $\mathrm{T}_{\mathrm{y}}$ to be the inputs and $\theta_{\mathrm{x}}, \beta_{\mathrm{x}}, \theta_{\mathrm{y}}$ and $\beta_{\mathrm{y}}$ to be the outputs of the system. By numbering the state 
variables, arbitrarily, we have;

$$
x_{1}=\theta_{x}, x_{2}=\beta_{x}, x_{3}=\theta_{y}, x_{4}=\beta_{y}, x_{5}=\dot{\theta}_{x}, x_{6}=\dot{\beta}_{x}, x_{7}=\dot{\theta}_{y}, \quad x_{8}=\dot{\beta}_{y}
$$

From equations (8) - (14) we get;

$$
\left\{\begin{array}{c}
\dot{\mathrm{x}}_{1}=\mathrm{x}_{5} \\
\dot{\mathrm{x}}_{2}=\mathrm{x}_{6} \\
\dot{\mathrm{x}}_{3}=\mathrm{x}_{7} \\
\dot{\mathrm{x}}_{4}=\mathrm{x}_{8} \\
\dot{\mathrm{X}}_{5}=\mathrm{vx}_{1}-\mathrm{wT}_{\mathrm{x}} \\
\dot{\mathrm{x}}_{6}=\mathrm{zx}_{1}-\mathrm{pT}_{\mathrm{x}} \\
\dot{\mathrm{x}}_{7}=\mathrm{vx}_{3}-\mathrm{wT}_{\mathrm{y}} \\
\dot{\mathrm{x}}_{8}=\mathrm{zx}_{3}-\mathrm{pT}_{\mathrm{y}}
\end{array}\right.
$$

where

$\mathrm{v}=\mathrm{c}_{1}, \quad \mathrm{w}=-\mathrm{c}_{2}, \quad \mathrm{z}=\mathrm{c}_{3}, \quad \mathrm{p}=-\mathrm{c}_{4}$

\section{SMC for ball-on-sphere system}

SMC design has 2 stages [29] and the relevance between the two stages is stated below:

i. $\quad$ Sliding surface design so that sliding movement satisfies design requirements.

ii. Control law designing so that system's state attracts the switching surface.

Let the sliding surface be defined as

$$
\mathrm{s}=\left(\frac{\mathrm{d}}{\mathrm{dt}}+\gamma\right)^{\mathrm{n}-1} \mathrm{e}
$$

where $\mathrm{e}=\mathrm{x}_{\mathrm{d}}-\mathrm{x}$ path error, $\mathrm{x}$ is the system path, $\mathrm{x}_{\mathrm{d}}$ is the reference path, $\gamma$ is strictly non-negative, and $\mathrm{n}$ is the order the system.

Then, $\mathrm{n}=2$ for $2 \mathrm{nd}$-order system, hence, the sliding surface is

$$
\mathrm{s}=\dot{\mathrm{e}}+\gamma \mathrm{e}
$$

which implies

$$
\dot{\mathrm{s}}=\ddot{\mathrm{e}}+\gamma \dot{\mathrm{e}}
$$

From equation (12)

$$
\dot{\mathrm{s}}=\ddot{\theta}_{\mathrm{xd}}-\mathrm{c}_{1} \theta_{\mathrm{x}}-\mathrm{c}_{2} \mathrm{~T}_{\mathrm{x}}+\gamma\left(\dot{\theta}_{\mathrm{xd}}-\dot{\theta}_{\mathrm{x}}\right)
$$

Setting equation (19) to zero, that is $\dot{\mathrm{s}}=0$, gives the equivalent control as;

$$
\mathrm{u}_{\mathrm{eq}}=\mathrm{c}_{2}^{-1}\left[\ddot{\theta}_{\mathrm{xd}}-\mathrm{c}_{1} \theta_{\mathrm{x}}+\gamma\left(\dot{\theta}_{\mathrm{xd}}-\dot{\theta}_{\mathrm{x}}\right)\right]
$$

The sliding mode control is

$$
\mathrm{u}_{\mathrm{SMC}}=\mathrm{u}_{\mathrm{eq}}+\mathrm{u}_{\mathrm{n}}
$$

where $u_{n}=k \operatorname{sgn}(s)$ is the switching control.

Then, the SMC law for the position of the ball along $\mathrm{x}$ and $\mathrm{y}$ directions is: 


$$
\left\{\begin{array}{l}
u_{S M C, b, x}=c_{2}^{-1}\left[\ddot{\theta}_{x d}-c_{1} \theta_{x}+\gamma\left(\dot{\theta}_{x d}-\dot{\theta}_{x}\right)+\operatorname{ksgn}(s)\right] \\
u_{S M C, b, y}=c_{2}^{-1}\left[\ddot{\theta}_{y d}-c_{1} \theta_{y}+\gamma\left(\dot{\theta}_{y d}-\dot{\theta}_{y}\right)+\operatorname{ksgn}(s)\right]
\end{array}\right.
$$

Similarly, from equation (13) and applying the same procedure, SMC law for the position sphere along $\mathrm{x}$ and $\mathrm{y}$ directions is:

$$
\left\{\begin{array}{l}
\mathrm{u}_{\mathrm{SMC}, \mathrm{s}, \mathrm{x}}=\mathrm{c}_{4}^{-1}\left[\ddot{\beta}_{\mathrm{xd}}-\mathrm{c}_{3} \theta_{\mathrm{x}}+\gamma\left(\dot{\beta}_{\mathrm{xd}}-\dot{\beta}_{\mathrm{x}}\right)+\mathrm{ksgn}(\mathrm{s})\right] \\
\mathrm{u}_{\mathrm{SMC}, \mathrm{s}, \mathrm{y}}=\mathrm{c}_{4}^{-1}\left[\ddot{\beta}_{\mathrm{yd}}-\mathrm{c}_{3} \theta_{\mathrm{y}}+\gamma\left(\dot{\beta}_{\mathrm{yd}}-\dot{\beta}_{\mathrm{y}}\right)+\mathrm{ksgn}(\mathrm{s})\right]
\end{array}\right.
$$

For the existence of a SM in a sliding manifold and for the system to attain, in finite of time and independent of the initial condition, the sliding manifold, this condition is to be met [14]:

$$
\dot{\mathrm{s} s} \leq-3|\mathrm{~s}|
$$

here 3 is a constant rigorously positive.

\section{Test for convergence on the sliding surface using Lyapunov's method}

Let $y=0$ be a point of equilibrium of $\dot{y}=h(y)$ and $h: J \rightarrow R^{n}$. Again, let $v_{n}: J \rightarrow R$ be a continuous function that is differentiable such that

i. $\quad \mathrm{v}_{\mathrm{n}}(0)=0$

ii. $\quad v_{n}(y)>0$ in $J-\{0\}$

iii. $\quad \dot{\mathrm{v}}_{\mathrm{n}}(\mathrm{y})<0$ in $\mathrm{J}-\{0\}$

Then $\mathrm{y}=0$ is "asymptotically stable" [8].

To satisfy equation (24), which is the reachability condition, let the control input be taken as

$$
\mathrm{T}_{\mathrm{x}}=\ddot{\theta}_{\mathrm{xd}}-\mathrm{c}_{1} \theta_{\mathrm{x}}+\gamma\left(\dot{\theta}_{\mathrm{xd}}-\dot{\theta}_{\mathrm{x}}\right)+\mathrm{ksgn}(\mathrm{s}) \text { and } c_{2}=1
$$

Substituting equation (25) into equation (19) gives

$$
\dot{\mathrm{s}}=-\operatorname{ksgn}(\mathrm{s}) \quad \text { but } \quad \operatorname{sgn}(\mathrm{s})=\frac{|\mathrm{s}|}{\mathrm{s}} \quad \text { which implies }
$$

$\dot{\mathrm{s}}=-\mathrm{k} \frac{|\mathrm{s}|}{\mathrm{s}}$. Consequently,

$$
\dot{\mathrm{s}} \mathrm{s}=-\mathrm{k}|\mathrm{s}|
$$

Assuming a function $\mathrm{v}_{\mathrm{n}}(\mathrm{y})$ exists of the state $\mathrm{y}$ over time $\mathrm{t}$ such that

$$
\left\{\begin{array}{c}
\mathrm{v}_{\mathrm{n}}(\mathrm{y})=\frac{1}{2}\{\mathrm{~s}(\mathrm{y})\}^{2} \\
\dot{\mathrm{v}}_{\mathrm{n}}(\mathrm{y})=\frac{\partial}{\partial \mathrm{t}}\left[\{\mathrm{s}(\mathrm{y})\}^{2}\right] \\
\dot{\mathrm{v}}_{\mathrm{n}}(\mathrm{y})=\dot{\mathrm{s} s}
\end{array}\right.
$$

It is evident from equations (26) and (27) that $\mathrm{v}_{\mathrm{n}}(0)=0, \mathrm{v}(\mathrm{y})>0, \dot{\mathrm{v}}_{\mathrm{n}}(\mathrm{y})<0$, and this implies asymptotic stability since $\mathrm{k}$ is a constant that is rigorously positive.

Hence, the reachability condition is satisfied and system state convergence to the sliding surface is guaranteed whenever the controller is given to the system.

Similarly, it can be shown that for the input control along the y-axis the reachability condition is satisfied and system state convergence to the sliding surface is guaranteed when the controller is given to the system.

\section{ST SMC for ball-on-sphere system}

A type of 2nd -order SMC known as the ST algorithm can be used as a technique for chattering reduction. The algorithm is as shown below [30]: 


$$
\mathrm{u}_{\mathrm{n}}=\mathrm{u}_{\mathrm{n} 1}+\dot{\mathrm{u}}_{\mathrm{n} 2}
$$

where

$$
\begin{gathered}
\mathrm{u}_{\mathrm{n} 1}=-\sqrt{\mathrm{k}} \sqrt{|\mathrm{s}|} \operatorname{sgn}(\mathrm{s}) \\
\dot{\mathrm{u}}_{\mathrm{n} 2}=-1.1 \mathrm{ksgn}(\mathrm{s})
\end{gathered}
$$

Here, $\mathrm{k}$ is gain which is positive and its value can be sufficiently large. To achieve good close-loop performance, this gain can be progressively increased.

For chattering reduction, the equivalent control and the super twisting algorithm can be coupled to give a good performance. Substituting (29) and (30) into (28) gives

$$
\mathrm{u}_{\mathrm{n}}=(-\sqrt{\mathrm{k}} \sqrt{|\mathrm{s}|} \operatorname{sgn}(\mathrm{s}))+(-1.1 \mathrm{ksgn}(\mathrm{s}))
$$

By coupling equation (22) and equation (31) we get the ST SMC law for the position of the ball along $\mathrm{x}$ and $\mathrm{y}$ directions as:

$$
\left\{\begin{array}{l}
\mathrm{u}_{\mathrm{SMC}, \mathrm{b}, \mathrm{x}}=\mathrm{c}_{2}^{-1}\left[\ddot{\theta}_{\mathrm{xd}}-\mathrm{c}_{1} \theta_{\mathrm{x}}+\gamma\left(\dot{\theta}_{\mathrm{xd}}-\dot{\theta}_{\mathrm{x}}\right)+(-\sqrt{\mathrm{k}} \sqrt{|\mathrm{s}|} \operatorname{sgn}(\mathrm{s}))+(-1.1 \mathrm{ksgn}(\mathrm{s}))\right] \\
\mathrm{u}_{\mathrm{SMC}, \mathrm{b}, \mathrm{y}}=\mathrm{c}_{2}^{-1}\left[\ddot{\theta}_{\mathrm{yd}}-\mathrm{c}_{1} \theta_{\mathrm{y}}+\gamma\left(\dot{\theta}_{\mathrm{yd}}-\dot{\theta}_{\mathrm{y}}\right)+(-\sqrt{\mathrm{k}} \sqrt{|\mathrm{s}|} \operatorname{sgn}(\mathrm{s}))+(-1.1 \mathrm{ksgn}(\mathrm{s}))\right]
\end{array}\right.
$$

Similarly, by coupling equation (23) and equation (31) we get the ST SMC law for the position of the sphere along $\mathrm{x}$ and y directions as:

$$
\left\{\begin{array}{l}
\mathrm{u}_{\mathrm{SMC}, \mathrm{s}, \mathrm{x}}=\mathrm{c}_{4}^{-1}\left[\ddot{\beta}_{\mathrm{xd}}-\mathrm{c}_{3} \theta_{\mathrm{x}}+\gamma\left(\dot{\beta}_{\mathrm{xd}}-\dot{\beta}_{\mathrm{x}}\right)+(-\sqrt{\mathrm{k}} \sqrt{|\mathrm{s}|} \operatorname{sgn}(\mathrm{s}))+(-1.1 \mathrm{ksgn}(\mathrm{s}))\right] \\
\mathrm{u}_{\mathrm{SMC}, \mathrm{s}, \mathrm{y}}=\mathrm{c}_{4}^{-1}\left[\ddot{\beta}_{\mathrm{yd}}-\mathrm{c}_{3} \theta_{\mathrm{y}}+\gamma\left(\dot{\beta}_{\mathrm{yd}}-\dot{\beta}_{\mathrm{y}}\right)+(-\sqrt{\mathrm{k}} \sqrt{|\mathrm{s}|} \operatorname{sgn}(\mathrm{s}))+(-1.1 \mathrm{ksgn}(\mathrm{s}))\right]
\end{array}\right.
$$

\section{Simulations, analysis, results, and discussion}

To control the system, the system's physical parameters are presented in Table 1 . These parameters are arbitrarily chosen for simulation.

Desired initial conditions are also specified as presented in Table 2. These parameters are also arbitrarily chosen for simulation.

The simulation was done using MATLAB/SIMULINK

Table 1. System’s considered parameters [27].

\begin{tabular}{|c|c|c|}
\hline Parameter & Value & Units \\
\hline Ball's mass $(\mathrm{m})$ & 0.06000 & $\mathrm{~kg}$ \\
\hline Ball's radius $(\mathrm{r})$ & 0.01250 & $\mathrm{~m}$ \\
\hline Sphere's radius $(\mathrm{R})$ & 0.15000 & $\mathrm{~m}$ \\
\hline Ball's moment of inertia $\left(\mathrm{I}_{\mathrm{b}}\right)$ & $3.75 \times 10^{-6}$ & $\mathrm{~kg} \cdot \mathrm{m}^{2}$ \\
\hline Sphere's moment of inertia $\left(\mathrm{I}_{\mathrm{B}}\right)$ & 0.99 & $\mathrm{~kg} \cdot \mathrm{m}^{2}$ \\
\hline Gravitational acceleration $(\mathrm{g})$ & 9.81 & $\mathrm{~m} / \mathrm{s}^{2}$ \\
\hline
\end{tabular}

Table 2. System's initial conditions of the system.

\begin{tabular}{|c|c|c|}
\hline Initial parameter & Value & Units \\
\hline$\theta_{\mathrm{x} 0}$ & 1 & radian \\
\hline$\beta_{\mathrm{x} 0}$ & 0 & radian \\
\hline$\theta_{\mathrm{y} 0}$ & 1 & radian \\
\hline$\beta_{\mathrm{y} 0}$ & 0 & radian \\
\hline$\dot{\theta}_{\mathrm{x} 0}$ & -2 & radian/s \\
\hline$\dot{\beta}_{\mathrm{x} 0}$ & 0 & radian/s \\
\hline$\dot{\theta}_{\mathrm{y} 0}$ & -2 & radian/s \\
\hline$\dot{\beta}_{\mathrm{y} 0}$ & 0 & radian/s \\
\hline
\end{tabular}




\section{A. Linear Controller}

Using the system's state space model, when a linear controller is applied, it is observed that the controller does not provide, while there is disturbance, origin's asymptotic stability but it provides origin's asymptotic stability, Fig 3. and Fig. 4, in the absence of disturbance. As it is observed from Fig 5. and Fig 6., the system states oscillate around zero with disturbance. Gain values of 3 and 4 were used for controlled-output and its derivative, respectively. sin $2 t$ is the applied disturbance.

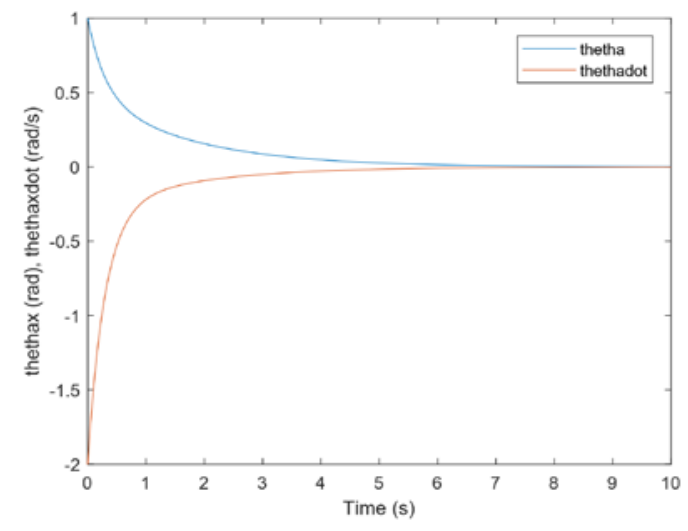

Fig 3. Response with a linear controller with no disturbance along x direction.

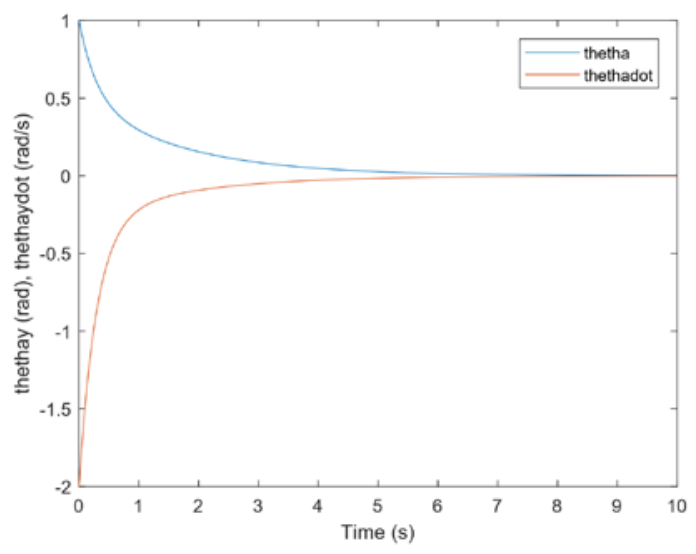

Fig 4. Response with a linear controller with no disturbance along y direction.

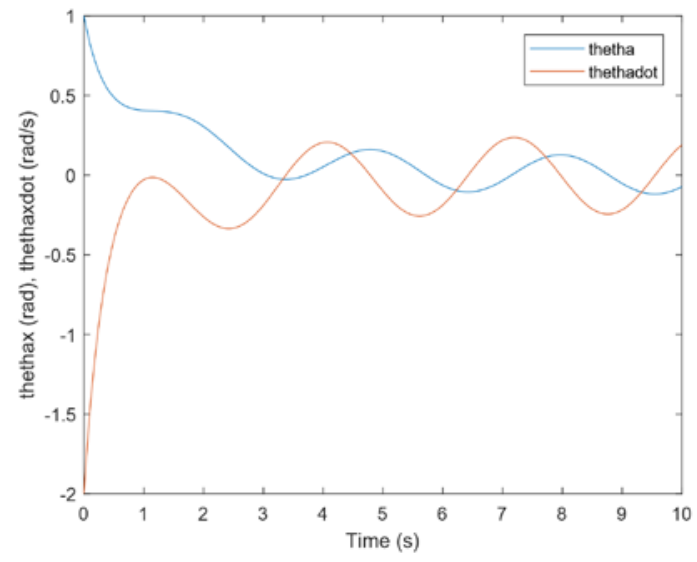

Fig 5. Response with a linear controller with disturbance along x direction 


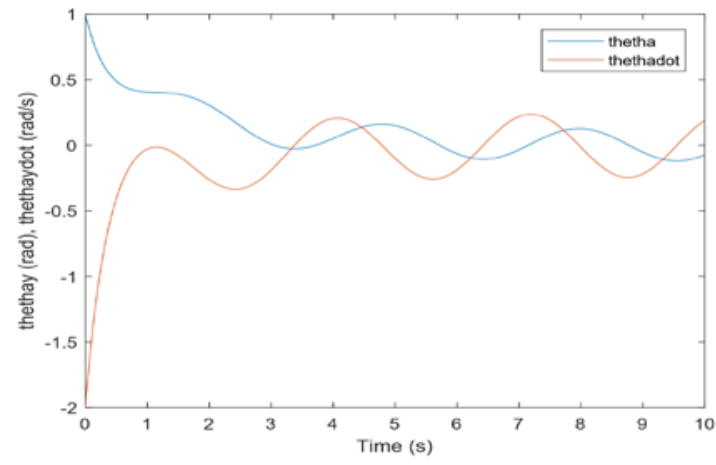

Fig 6. Response with a linear controller with no disturbance along y direction.

\section{B. SMC}

Using same system parameters, as for the linear controller, using the SMC the states of the system attain, in finite time, zero even while there is disturbance. Comparing Fig 3., Fig 4. and Fig 7., Fig. 8, the settling time of the SM response is noticed to be smaller than that of the linear control. Fig 9. and Fig 10. Show sliding mode controller sliding variable. Fig 11. and Fig 12. show the sliding phase and the reaching phase $(\mathbf{s} \dot{s}<0)$. Fig 13. and Fig 14. show the zoomed view of the sliding phase and the reaching phase which show a zigzag motion that indicates the presence of chattering. Fig 15 . and Fig 16. show the effort of the sliding mode controller.

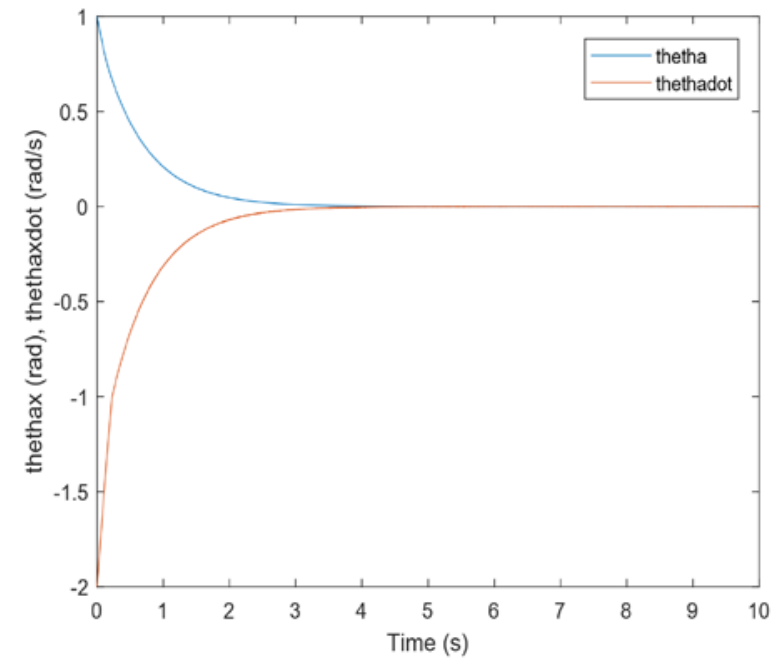

Fig 7. Response with SMC with disturbance along x direction.

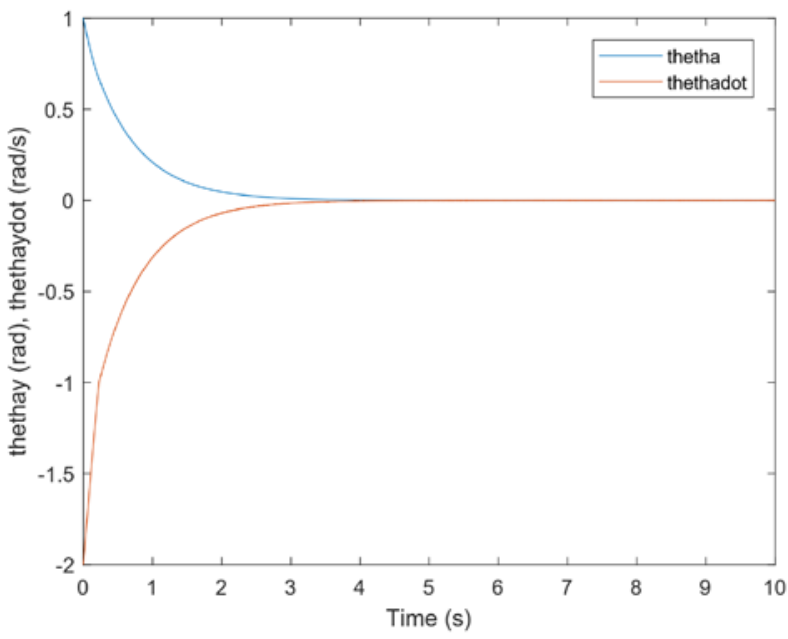

Fig 8. Response with SMC with disturbance along y direction. 


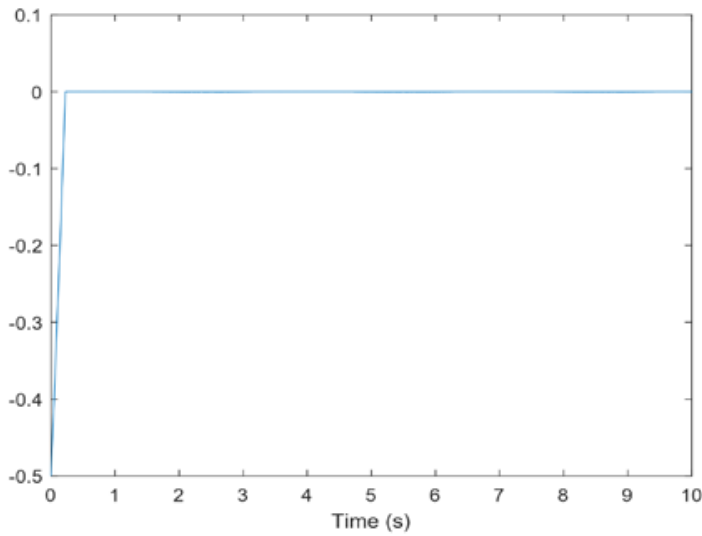

Fig 9. Sliding variable along $\mathrm{x}$ direction.

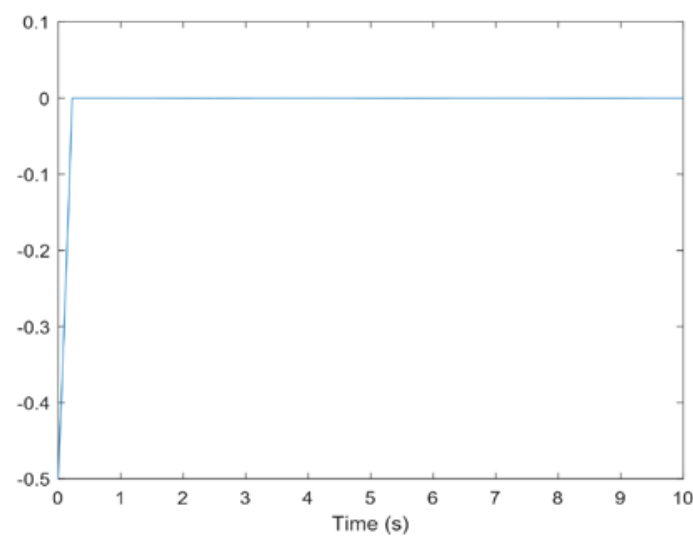

Fig 10. Sliding variable along y direction.

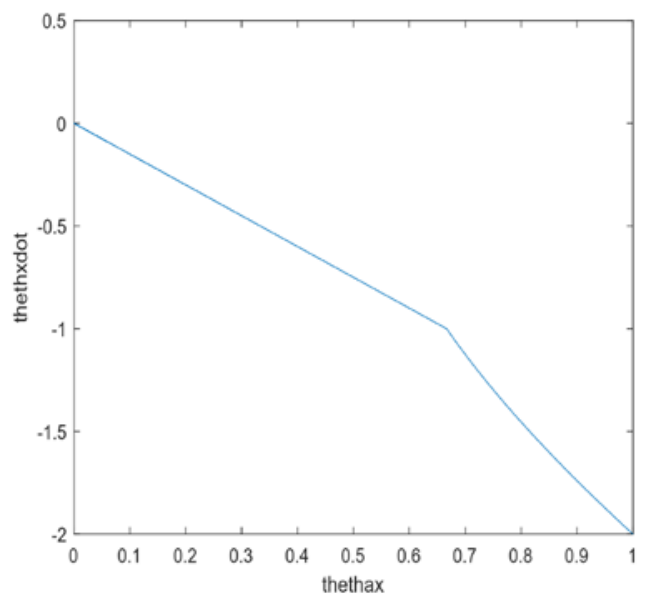

Fig 11. Reaching and sliding phases along $\mathrm{x}$ direction. 


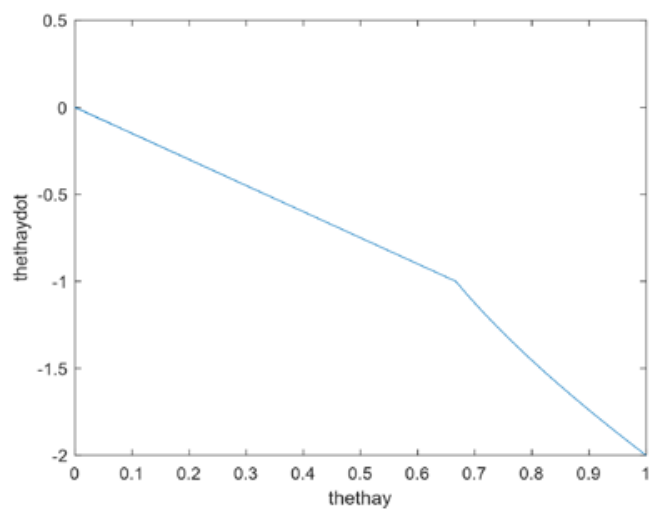

Fig 12. Reaching and sliding phases along y direction.

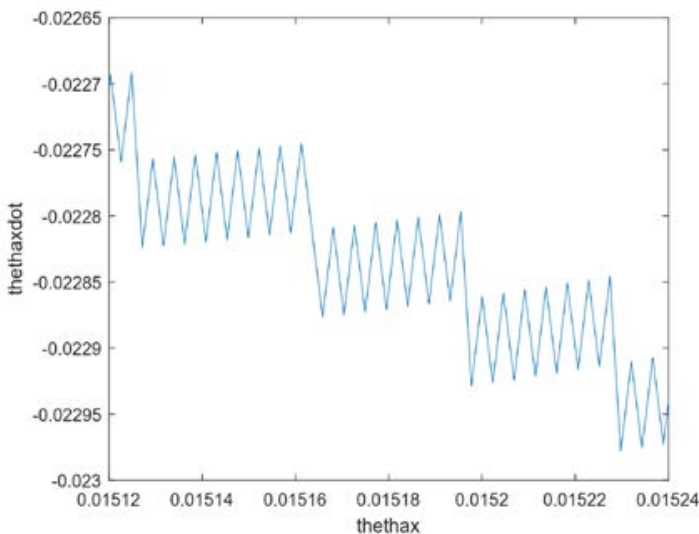

Fig 13. Zoomed view of reaching and sliding phases along $\mathrm{x}$ direction.

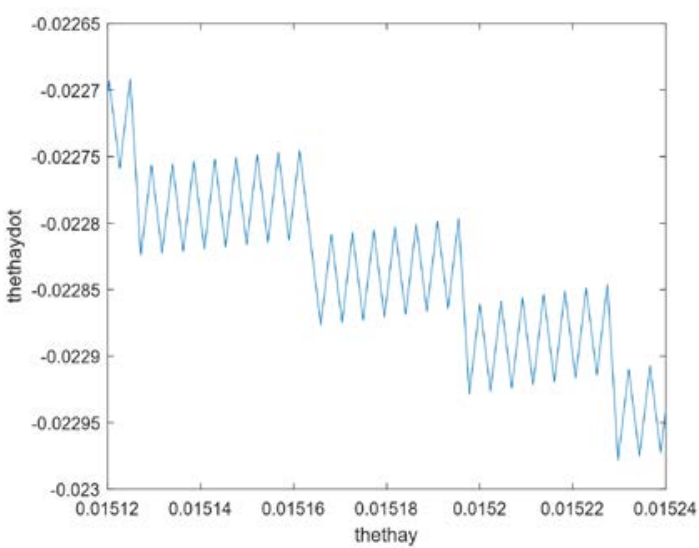

Fig 14. Zoomed view of reaching and sliding phases along y direction. 


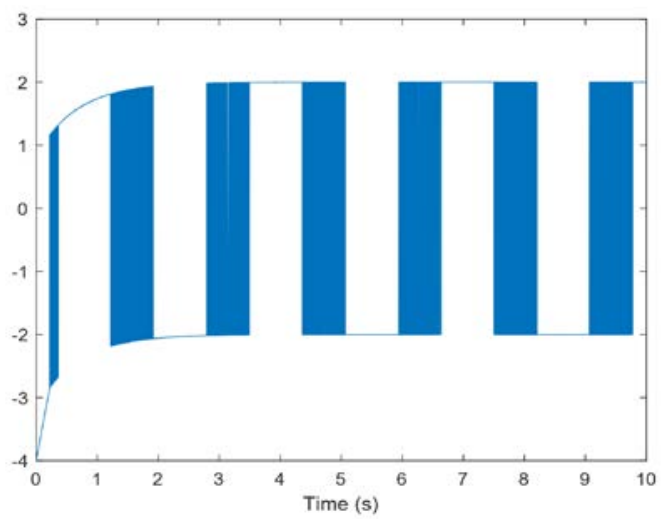

Fig 15. SMC along $\mathrm{x}$ direction.

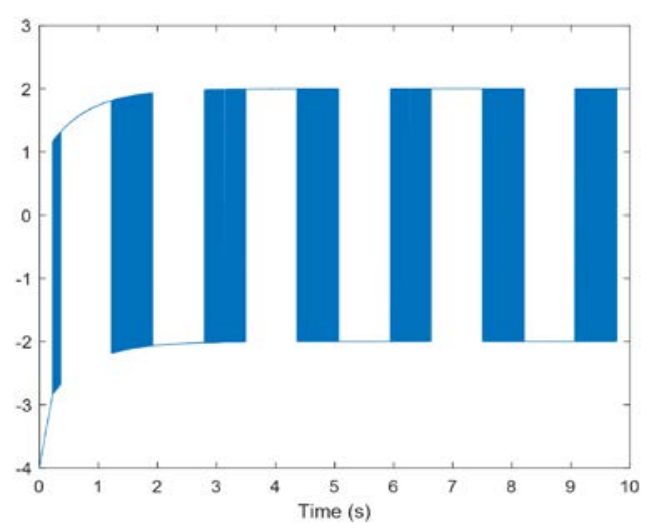

Fig 16. SMC along y direction.

\section{2nd-order SMC}

Fig 17., Fig 18. show the 2nd -order SMC response. It is noticed that system states attain, in finite time, zero. Comparing with the SMC's response, Fig 7. and Fig 8., it is evident that the controlled-output and its derivative reach zero faster with 2nd -order SMC. Fig 19. and Fig 20. show the sliding variable for the 2nd -order SMC. And Fig 21. and Fig 22. show the 2nd -order SMC effort where system dynamical collapse is attained in the 2nd -order SM since dynamics of systems are equal and zero.

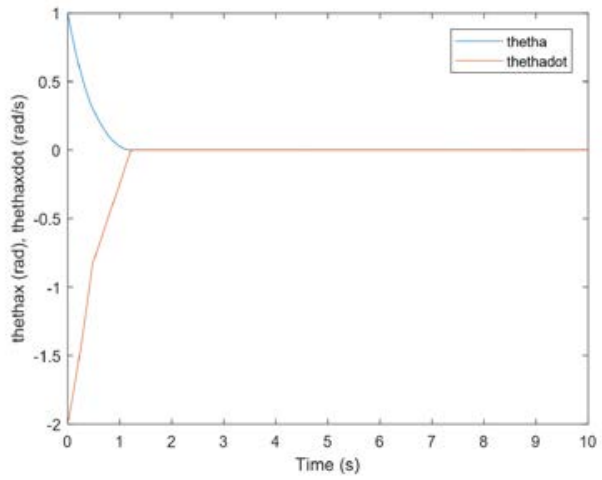

Fig 17. Response with 2nd -order SMC along $\mathrm{x}$ direction. 


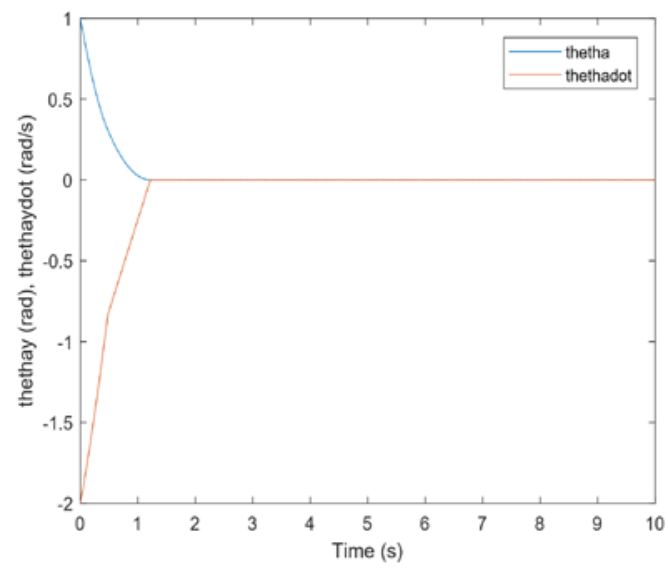

Fig 18. Response with 2nd -order SMC along y direction.

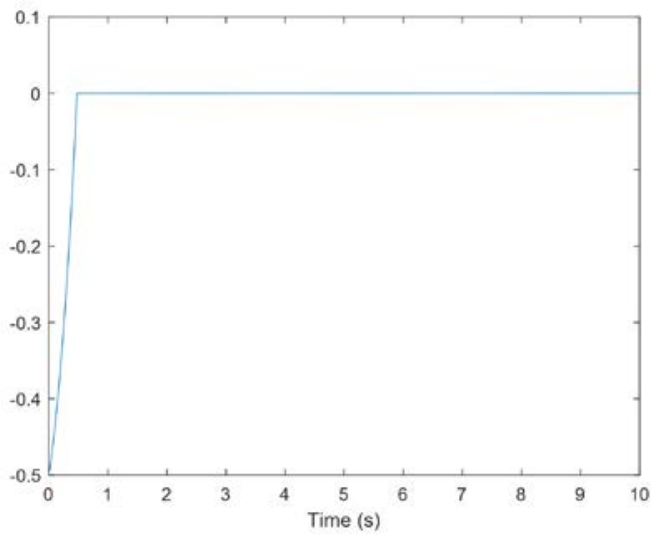

Fig 19. Second-order sliding variable along $\mathrm{x}$ direction.

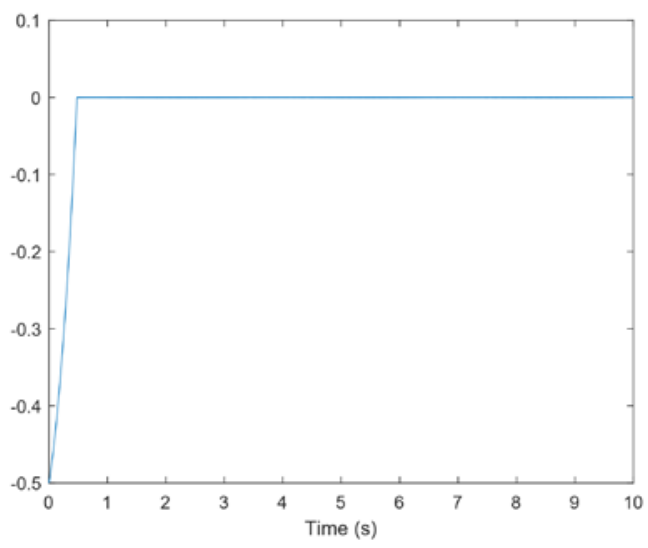

Fig 20. Second-order sliding variable along y direction. 


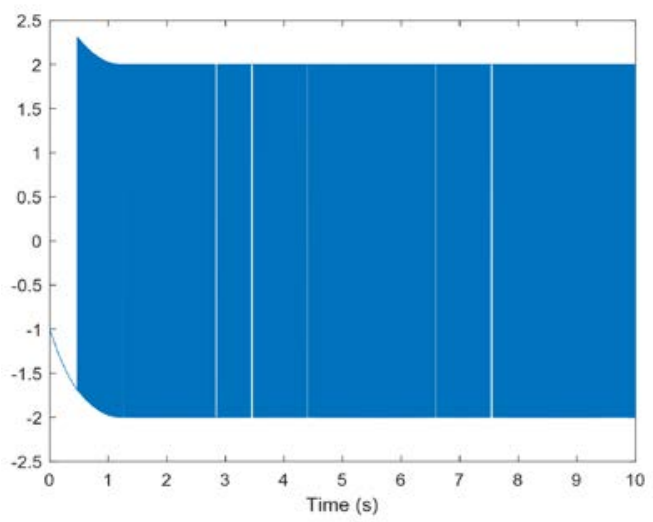

Fig 21. 2nd -order SMC along $\mathrm{x}$ direction.

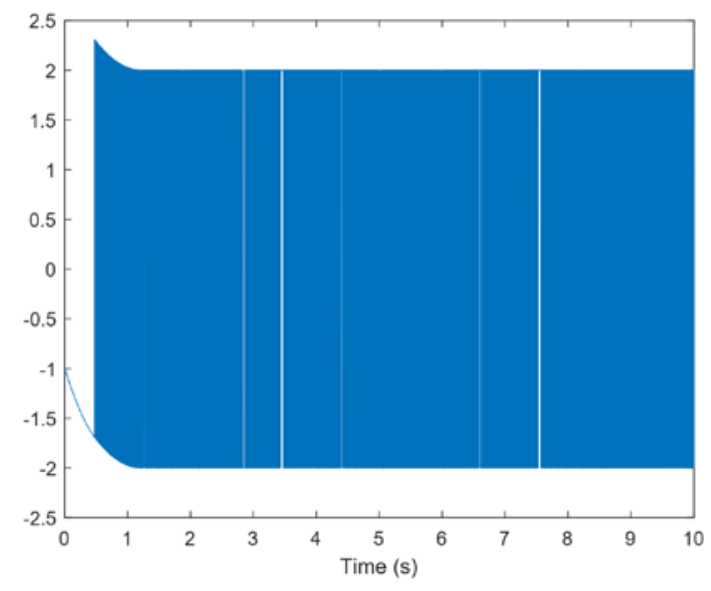

Fig 22. 2nd -order SMC along y direction.

\section{ST SMC}

Fig 23., Fig 24. and Fig 25., Fig 26, show the ST sliding variable and the ST SMC, respectively. The reference trajectory used for this control is 2cost. It is noticed that the ST SMC has effectively reduced the chattering amplitude and the sliding variable is driven, in finite time, to zero.

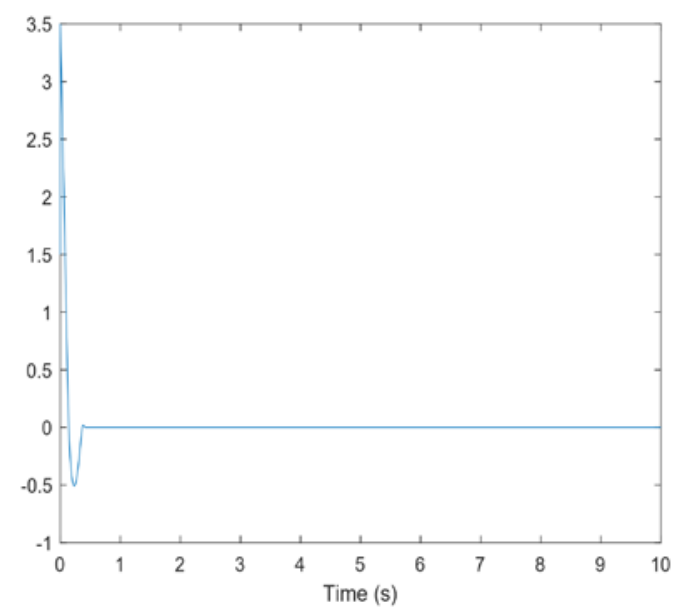

Fig 23. ST sliding variable along $\mathrm{x}$ direction. 


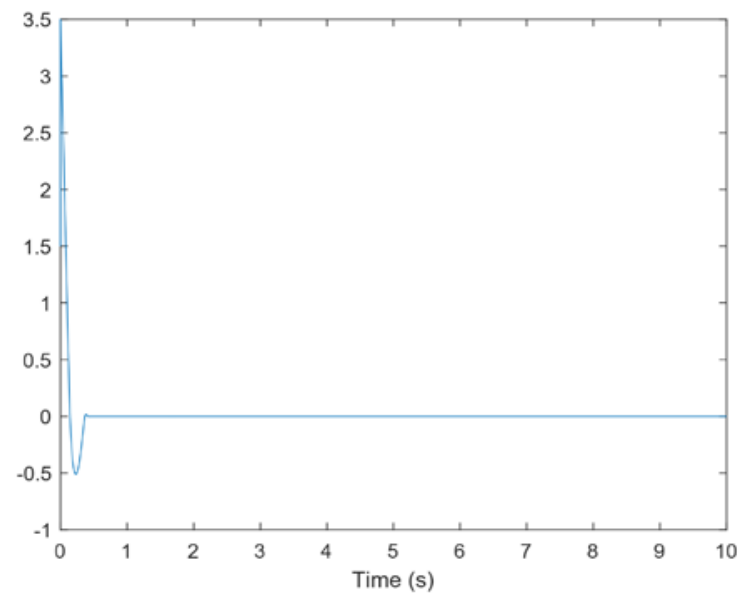

Fig 24. ST sliding variable along y direction.

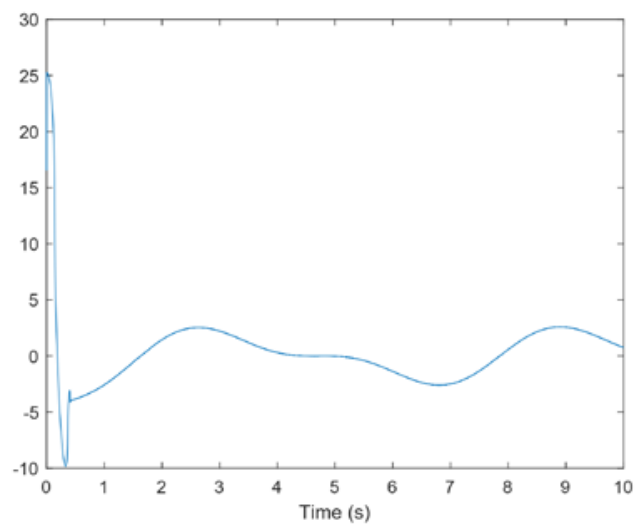

Fig 25. ST SMC along $x$ direction.

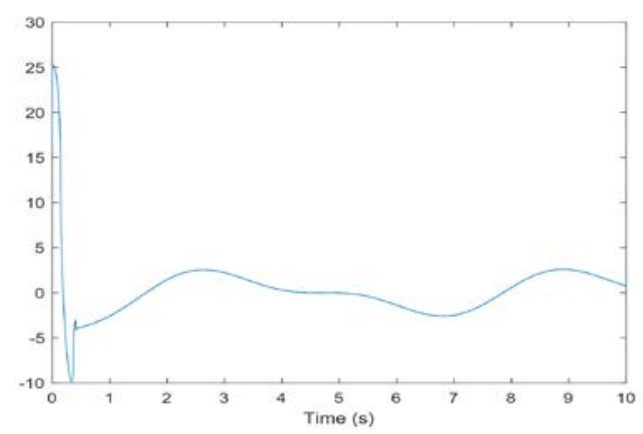

Fig 26. ST SMC along y direction.

\section{Conclusion}

The paper aimed to design a SMC for ball-on-sphere system. The aim was achieved by first, developing the mathematical model of the system, then designing a SMC, testing for convergence on the sliding surface, and designing a ST SMC for chattering reduction. The responses show that even with disturbance a SMC can provide origin's asymptotic stability, which confirms the robustness and convergence of SMC in finite time. The $2^{\text {nd }}$-order SMC provides faster asymptotic stability of the origin. Super twisting SMC is observed to be an efficient chattering reduction method. Chattering is the major problem with SMC. This work provides an efficient way of reducing chattering which gives an addition to the current state of the method. 


\section{References}

[1] K. Furuta, M. Yamakita, and S. Kobayashi, “Swing-up Control of Inverted Pendulum Using Pseudo-State Feedback,” Proc. Inst. Mech. Eng. Part J. Syst. Control Eng., vol. 206, no. 4, pp. 263-269, Nov. 1992, doi: 10.1243/PIME_PROC_1992_206_341_02.

[2] J. Hauser, S. Sastry, and P. Kokotović, "Nonlinear control via approximate input-output linearization: The ball and beam example,” Autom. Control IEEE Trans. On, vol. 37, pp. 392-398, Apr. 1992, doi: 10.1109/9.119645.

[3] M. L. Moore, J. T. Musacchio, and K. M. Passino, "Genetic adaptive control for an inverted wedge: experiments and comparative analyses,” Eng. Appl. Artif. Intell., vol. 14, no. 1, pp. 1-14, Feb. 2001, doi: 10.1016/S0952-1976(00)00047-6.

[4] E. Zakeri, S. Moezi, and Y. Bazargan-lari, "Control of a Ball on Sphere System with Adaptive Feedback Linearization method for regulation purpose,” MAJLESI J. Mechatron. Syst. 102013 23, vol. 2, Oct. 2013.

[5] M. Ho, Y. Tu, and H. Lin, "Controlling a ball and wheel system using full-state-feedback linearization [Focus on Education]," Control Syst. IEEE, vol. 29, pp. 93-101, Nov. 2009, doi: 10.1109/MCS.2009.934085.

[6] C. Graf and T. Röfer, “A Closed-loop 3D-LIPM Gait for the RoboCup Standard Platform League Humanoid,” p. 5, 2010.

[7] C. Edwards, A. Akoachere, and S. K. Spurgeon, "Sliding-mode output feedback controller design using linear matrix inequalities,” IEEE Trans. Autom. Control, vol. 46, no. 1, pp. 115-119, Jan. 2001, doi: 10.1109/9.898702.

[8] J.-J. E. Slotine and W. Li, Applied nonlinear control. Englewood Cliffs, N.J: Prentice-Hall, 1991.

[9] A. Rhif, Z. Kardous, and N. B. Braiek, “A PID-Sliding Mode Control Design for a Coupled Tank,” p. 6, 2012.

[10] H. Brandtstadter, "Sliding Mode Control of Electromechanical Systems,” p. 140.

[11] W. Perruquetti and J. P. Barbot, Eds., Sliding mode control in engineering. New York: M. Dekker, 2002.

[12] F. Piltan, N. Sulaiman, M. Rashidi, Z. Tajpaikar, and P. Ferdosali, "Design and Implementation of Sliding Mode Algorithm: Applied to Robot Manipulator-A Review,” Int. J. Robot. Autom., p. 18, 2011.

[13] C. T. Heng et al., "DESIGN AND ANALYSIS OF SUPER TWISTING SLIDING MODE CONTROL FOR MACHINE TOOLS,” J. Teknol., vol. 78, no. 10-3, Oct. 2016, doi: 10.11113/jt. v78.9758.

[14] S.-Y. Liu, Y. Rizal, and M.-T. Ho, "Stabilization of a Ball and Sphere System Using Feedback Linearization and Sliding Mode Control,"p. 6.

[15] K. J. Burnham, A. S. I. Zinober, and A. J. Koshkouei, "Dynamic sliding mode control design,” IEE Proc. - Control Theory Appl., vol. 152, no. 4, pp. 392-396, Jul. 2005, doi: 10.1049/ip-cta:20055133.

[16] A. Zebardast and H. Ghadiri, “DC Motor Control Using Sliding Mode Method,” Electr. Comput. Eng., p. 7, 2013.

[17] M. Idrees, S. Ullah, and S. Muhammad, "Sliding mode control design for stabilization of underactuated mechanical systems," Adv. Mech. Eng., vol. 11, no. 5, p. 168781401984271, May 2019, doi: 10.1177/1687814019842712.

[18] S. Wen, M. Z. Q. Chen, Z. Zeng, X. Yu, and T. Huang, "Fuzzy Control for Uncertain Vehicle Active Suspension Systems via Dynamic Sliding-Mode Approach,” IEEE Trans. Syst. Man Cybern. Syst., vol. 47, no. 1, pp. 24-32, Jan. 2017, doi: 10.1109/TSMC.2016.2564930.

[19] S. Jian, L. Zhitao, and S. Hongye, “A second-order sliding mode control design for bidirectional DCDC converter," in 2017 36th Chinese Control Conference (CCC), Dalian, China, Jul. 2017, pp. 9181-9186, doi: 10.23919/ChiCC.2017.8028819.

[20] Z. Feng and J. Fei, “Design and analysis of adaptive Super-Twisting sliding mode control for a microgyroscope,” PLOS ONE, vol. 13, no. 1, p. e0189457, Jan. 2018, doi: 10.1371/journal.pone.0189457.

[21] Y.-W. Liang, S.-D. Xu, and T.-C. Chu, "Robust Control of the Robot Manipulator via an Improved Sliding Mode Scheme,” in 2007 International Conference on Mechatronics and Automation, Harbin, China, Aug. 2007, pp. 1593-1598, doi: 10.1109/ICMA.2007.4303787.

[22] V. I. Utkin, “Sliding mode control design principles and applications to electric drives,” IEEE Trans. Ind. Electron., vol. 40, no. 1, pp. 23-36, Feb. 1993, doi: 10.1109/41.184818.

[23] V. M. Panchade, L. M. Waghmare, B. M. Patre, and P. P. Bhogle, "Sliding Mode Control of DC Drives," in 2007 International Conference on Mechatronics and Automation, Harbin, China, Aug. 2007, pp. 1576-1580, doi: 10.1109/ICMA.2007.4303784.

[24] K. D. Young, “A Control Engineer’s Guide to Sliding Mode Control,” IEEE Trans. CONTROL Syst. Technol., vol. 7, no. 3, p. 15, 1999.

[25] M. Moarref, M. Saadat, and G. Vossoughi, "Mechatronic design and position control of a novel ball and plate system,” in 2008 16th Mediterranean Conference on Control and Automation, Ajaccio, France, Jun. 2008, pp. 1071-1076, doi: 10.1109/MED.2008.4602212.

[26] S. A. Moezi, E. Zakeri, Y. Bazargan-Lari, and M. Khalghollah, "Fuzzy Logic Control of a Ball on Sphere System,” Adv. Fuzzy Syst., vol. 2014, pp. 1-6, 2014, doi: 10.1155/2014/291430.

[27] E. Zakeri, A. Ghahramani, and S. Moezi, “Adaptive Feedback Linearization Control of a Ball on Sphere System,” p. 5.

[28] A. Tewari, Modern control design with MATLAB and SIMULINK. Chichester; New York: John Wiley, 2002.

[29] V. Utkin, "Variable structure systems with sliding modes,” IEEE Trans. Autom. Control, vol. 22, no. 2, pp. 212-222, Apr. 1977, doi: 10.1109/TAC.1977.1101446.

[30] H. U. Suleiman, M. B. Murazu, T. A. Zarma, A. T. Salawudeen, S. Thomas, and A. A. Galadima, "Methods of Chattering Reduction in Sliding Mode Control: A Case Study of Ball and Plate System," in 2018 IEEE 7th International Conference on Adaptive Science \& Technology (ICAST), Accra, Aug. 2018, pp. 1-8, doi: 10.1109/ICASTECH.2018.8506783. 


\section{Authors' Profiles}

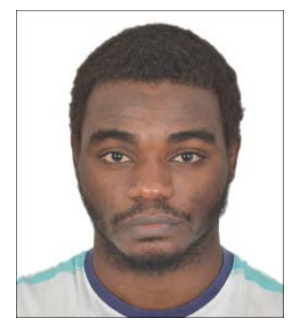

Usman Mohammed is a student in the Department of Electrical and Electronics Engineering, Nile University of Nigeria, Abuja, Nigeria. He completed his Bachelor's degree in Physics in 2016 at Fatih University, Istanbul, Turkey and Postgraduate Diploma (PGD) in Electrical and Electronics Engineering in 2019 at Nile University of Nigeria, Abuja, Nigeria. Currently, he is pursuing a Master's degree in Electrical and Electronics Engineering in Nile University of Nigeria, Abuja, Nigeria.

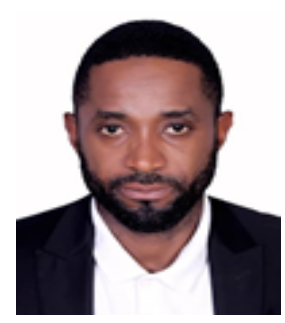

Suleiman Usman Hussein received his Bachelor of Engineering degree in Electrical and Electronic Engineering from the Federal University of Agriculture, Makurdi, Nigeria in 2006 and M.Sc. Degree in Applied Instrumentation and Control from Glasgow Caledonian University, Glasgow, UK in 2012. He received his Ph.D. in Control Engineering from Ahmadu Bello University, Zaria, Nigeria in 2017. He is currently a lecturer in the Department of Electrical and Electronic Engineering, Nile University of Nigeria, Abuja, Nigeria and also work with National Space Research and Development Agency, Abuja, Nigeria. His research interest includes Linear and Nonlinear Systems, System Modeling, Instrumentation, Optimal Control, Classical Control, Adaptive Control, Wireless Sensor Network, and Artificial Intelligence.

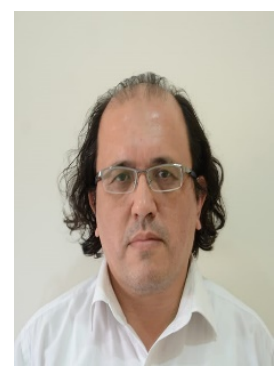

Gokhan Koyunlu is currently working as a Senior Lecturer at Computer Engineering Department, Nile University of Nigeria, Abuja. He has a Ph.D. in Applied Mathematics (2014) at Fatih University, Istanbul with Modelling and Simulation over Thermodynamic Systems. He has also specialized in Fractional Conformable Partial Differential Equations, Nonlinear Systems. He has many publications as international. He has presented at both national and international conferences. His research interests include Numerical Methods, Random Stochastic, Signal and Systems, Partial Differential Equations, and Applications over the various engineering systems. Also, He thought several undergraduate and postgraduate engineering courses.

How to cite this paper: Usman Mohammed, Suleiman U. Hussein, Gokhan Koyunlu. "Stabilization of Ball-On-Sphere System with Super Twisting (ST) Sliding Mode Control (SMC) as a Method of Chattering Reduction", International Journal of Engineering and Manufacturing (IJEM), Vol.10, No.5, pp.1-17, 2020. DOI: 10.5815/ijem.2020.05.01 